\title{
An international survey of medical ethics curricula in Asia
}

Michio Miyasaka, Akira Akabayashi, Ichiro Kai and Gen Ohi Niigata University, Niigata City, The Universi of Tokyo, Tokyo and The National Institute for Environmental Studies, Tsukuba City, fapan

\begin{abstract}
Setting-Medical ethics education has become common, and the integrated ethics curriculum has been recommended in Western countries. It should be questioned whether there is one, universal method of teaching ethics applicable worldwide to medical schools, especially those in non-Western developing countries.

Objective-To characterise the medical ethics curricula at Asian medical schools.

Design-Mailed survey of 206 medical schools in China, Hong Kong, Taiwan, Korea, Mongolia, Philippines, Thailand, Malaysia, Singapore, Indonesia, Sri Lanka, Australia and New Zealand. Participants-A total of 100 medical schools responded, a response rate of $49 \%$, ranging from $23 \%$ - $100 \%$ by country.

Main outcome measures-The degree of integration of the ethics programme into the formal medical curriculum was measured by lecture time; whether compulsory or elective; whether separate courses or unit of other courses; number of courses; schedule; total length, and diversity of teachers' specialties.

Results-A total of 89 medical schools (89\%) reported offering some courses in which ethical topics were taught. Separate medical ethics courses were mostly offered in all countries, and the structure of vertical integration was divided into four patterns. Most deans reported that physicians'obligations and patients'rights were the most important topics for their students. However, the evaluation was diverse for more concrete topics.

Conclusion-Offering formal medical ethics education is a widespread feature of medical curricula throughout the study area. However, the kinds of programmes, especially with regard to integration into clinical teaching, were greatly diverse.

(Fournal of Medical Ethics 1999;25:514-521)
\end{abstract}

Keywords: Medical ethics education; curriculum survey; medical school; Asia

\section{Introduction}

In the last two decades, formal ethics education has become one of the common features of medf cal curricula in many Western countries. ${ }^{1-9}$ The formation of a formal programme led to a general empirical understanding of how medical ethics should be taught. In the United Kingdom the Institute of Medical Ethics recommended tha medical ethics teaching should recur at regular intervals throughout medical teaching, and the time should be set aside within existing teaching for ethical reflection relevant to each stage offor student's experience. ${ }^{2}$ Miles and colleagues inthe USA argued similarly that ethics education shoūm be conceptually coherent, vertically and horizo tally integrated through preclinical and clinicgi training, multidisciplinary, academically rigorous, and should demonstrate humane and value conscious medical practice. ${ }^{3}$ Thus, the integration of ethics into the formal curriculum has become the standard recommended programme design off medical ethics education.

However, examples of well-integrated ethi programmes, quite often found in the literature, are mostly limited to Western industrialised cou tries. Few have questioned whether this standa\&d programme design is universal, applicable worl $\overrightarrow{\mathrm{E}}-$ wide to all medical schools, especially to those ho non-Western developing countries. The fund mental changes in medical ethics are usua attributed to social factors common to Western developed countries, namely the novel moral view of respect for patient's autonomy; the develo? ment of high-tech medical technology, and thet shift of major causes of death from acute curable diseases to chronic incurable ones, which hae forced physicians to think of therapeutic optiofs concerning patients' quality of life. ${ }^{10-14}$ In many developing countries, acute diseases are st killing many people, and therapeutic options co $\overrightarrow{0}-$ cerning comfortable quality of life are not realis for many people. Furthermore, individualis 
patient choice in clinical settings is not usual in non-Western countries, even today. Some Japanese scholars have criticised Western bioethics as placing too much weight on the principle of respect for autonomy that poorly fits the EastAsian ethos, which appreciates human interaction and communitarian empathy. ${ }^{15} 16$

If Western individualistic ethics has promoted formal medical ethics education, and if it is really unacceptable for the South and the East, it could be assumed that formal medical ethics education is neither common, nor even needed in most Asian countries. On the other hand, taking into account that most issues in medical ethics, such as organ transplantation and termination of life support, are now faced in Asian countries, and that the worldwide trade of medical technology has created a greater disparity in the distribution of health care resources, even within countries, it could be argued that Asian medical schools should prepare their students for ethical dilemmas, and indeed, for ethical dilemmas that could be much more complicated than in the West.

This study was designed to survey the medical ethics programmes of medical schools in the East, South-east, South Asia, and Oceania. The purpose of the study is to analyze how much ethics education is formally given, and how much is integrated into the medical curriculum.

\section{Methods}

SUBJECTS

We included all medical schools of the area which appeared in the World Health Organisation's World Directory of Medical Schools. ${ }^{17}$ Medical schools which specified they taught only traditional medicine were excluded. A four-page questionnaire was developed and sent to the dean or the president of the medical school. The initial mailing was made in November 1994, and four months later, a follow-up mailing was sent to non-respondents. The last response was received in October 1995. The mailing included an introductory letter. The letter and the questionnaire were in English. In a separate study, Japanese data were collected using a Japanese translation of the questionnaire used in this survey, and were submitted elsewhere. ${ }^{18}$ Part of the Japanese data was used to make statistical comparisons in this report. In Taiwan, where no data were cited in the directory, Dr Tai-Yuan Chiou of Taiwan University kindly informed us of the mailing addresses of all of the ten medical schools at that time.

\section{QUESTIONNAIRE AND ANALYTIC TECHNIQUES}

The questionnaire consisted of two parts. One addressed the programme of medical ethics or similar courses. Deans were asked to fill in the name of the course, school years in which the course was offered, the length of the course, whether it was compulsory or elective, and teachers' specialties. The second part asked the personal opinion of the dean on: ethics education; the degree of satisfaction with ethics education at his/her school; the importance of ethics education compared with other subjects; what kind of programme he/she would like to see and what kind of backgrounds he/she would prefer teachers to have, and what lecture topics he/she regarded as desirable for students. Respondents were required to note their nationality, sex, age, religion, specialty, the number of students in a school year, the number of full-time teachers, total school years (duration of medical degree course), and during which school years bed-side teaching was scheduled.

A "separate medical ethics course" was defined as a course whose title contained both (1) words representing medicine/medical care, ie "medicine", "health", "physician", "patient", "clinic", and (2) words representing ethics/moral philosophy, ie "ethics", "moral", "rule", "value". Other courses were categorised as "medicine related courses"; these were courses whose title contained only medicine-related words, or as "other courses"; these were courses whose titles included no medicine-related words.

We separated the medical degree course into three segments: before, during, and after bed-side teaching (BST) school years. The "BST school years" were defined as including school years at the beginning and end of BST, and all school years in between. Therefore, if BST was offered in the second and the fourth years, the third year was also regarded as "during BST".

Teachers' specialties were categorised into four categories; (1) physician/health professional; (2) philosopher/ethicist; (3) theologian/priest/monk, and (4) lawyer/ jurist/social scientist. Interdisciplinary backgrounds were identified by combination of the four categories. For instance, "medical ethics" was coded as "(1) and (2)". We didn't distinguish between the following two cases: (A) where one teacher had two or more backgrounds, and (B) where two or more teachers took part, but each of them had one-but a differentbackground.

With regard to Singapore and Mongolia, both of which had only one medical school, the country data are not shown in this report. 


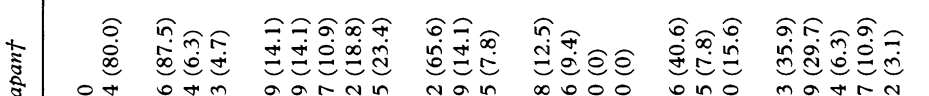

कิ

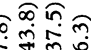

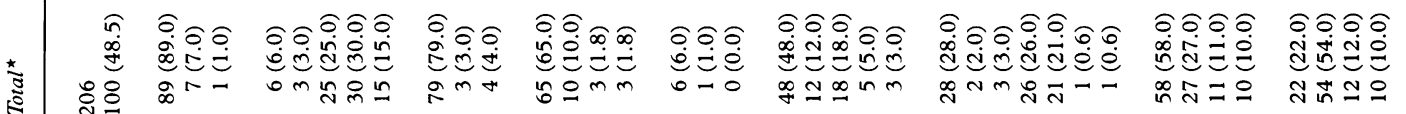

๑ิ

ลิ $ิ$

อิ

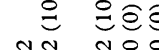

อิอิธ่ำ

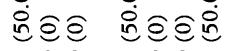

î.

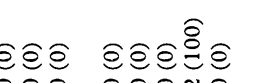

ธิ

ธิ

ธิธ

ํํำ仓ิ

त

Rล

กิก

ㄷ.

อิอย氖它

:

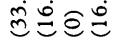

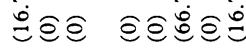

ำ

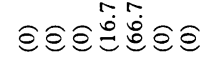

ำ

กิก

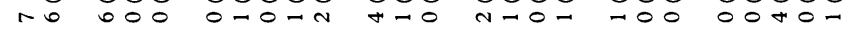

oo-too tmoo

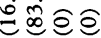

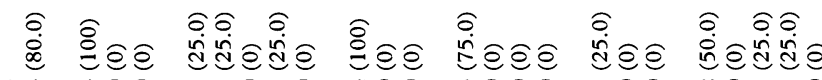

อิธิ

วิ $ิ$ อิ

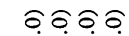

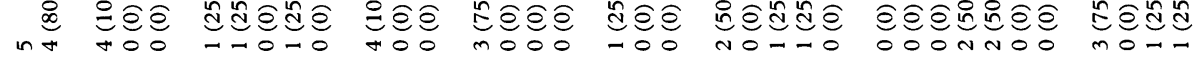

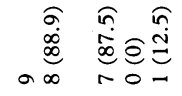

กิกิว

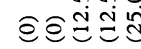

กิกิก กิอก กิ

กิ

\section{กิธิก}

\section{กิ กิ}

อิก

O०-ニN in

ma

eㄹㅇำ

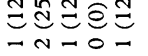

चอํํำ

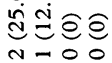

กิ

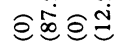

กิ อ

วิำ

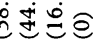
กิร

อิํํㅇํㅇ

กิก

हैं

กิ

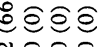

กิกิิฺ

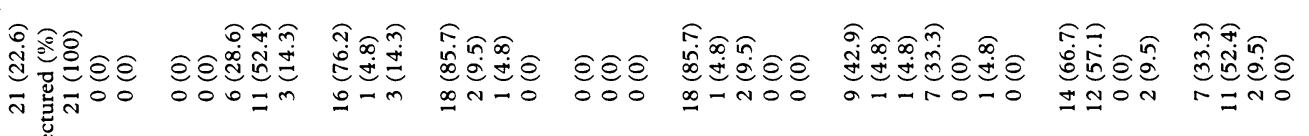

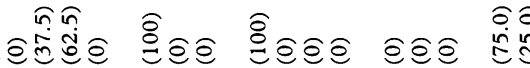
อิด กิ กิด

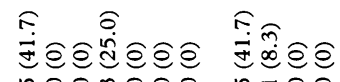

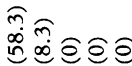

วิกิ์

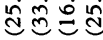

$m+N m$ 
สุo

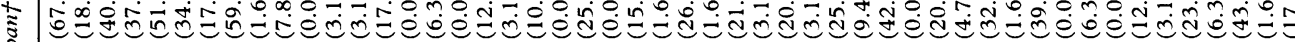
ई

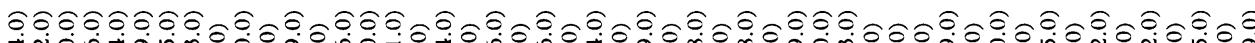

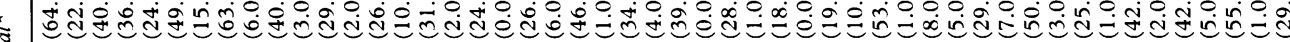

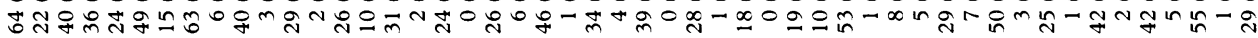

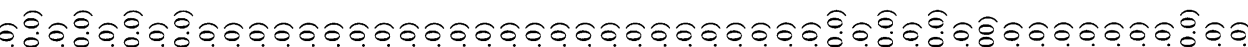
en 0-0-0-0-0000000000000000000000000-0-0-0N0000000-00

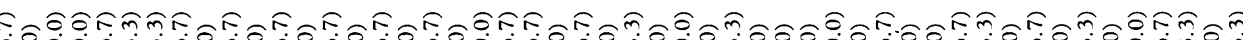

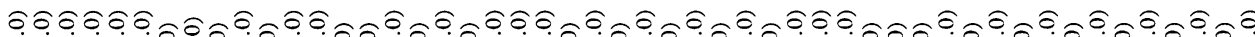

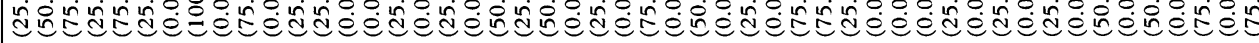

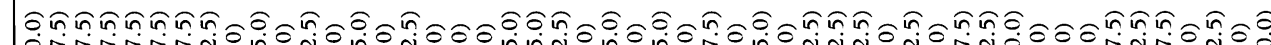

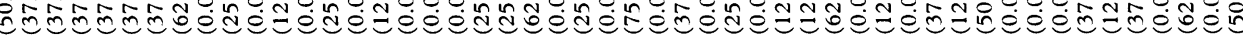
tmmmmmminONO-ONO-OOONNInONOOOMONO- - InO-OM-HOOOM-moinot

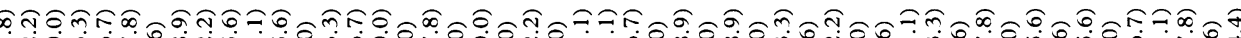

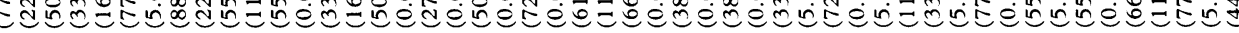

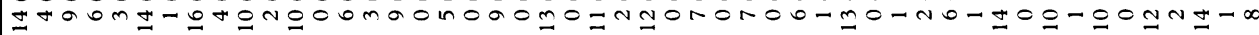

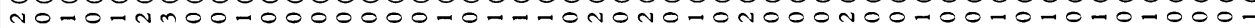

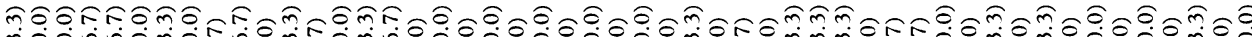

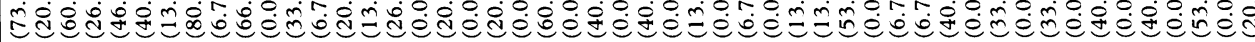

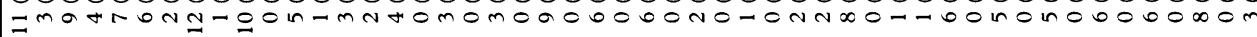

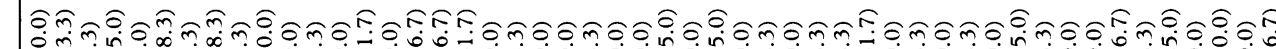

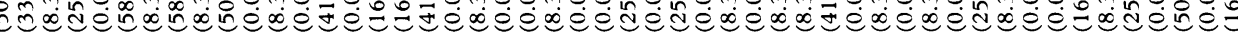

突这

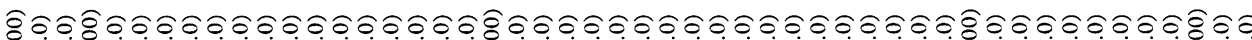

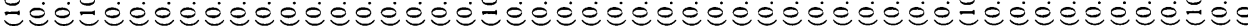
- $00-000000000000000-000000000000000000-00000000-00$

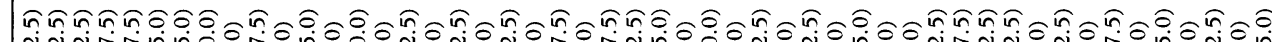

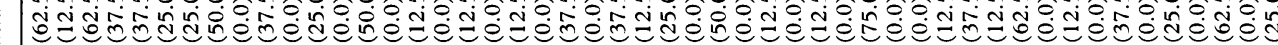

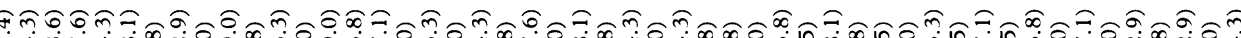

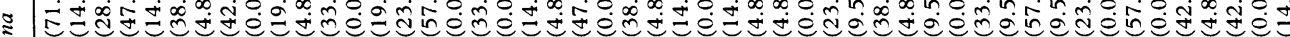

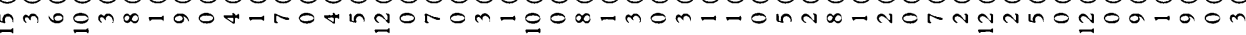

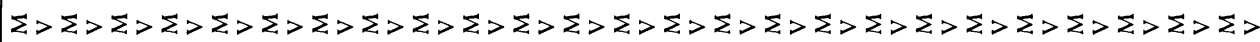




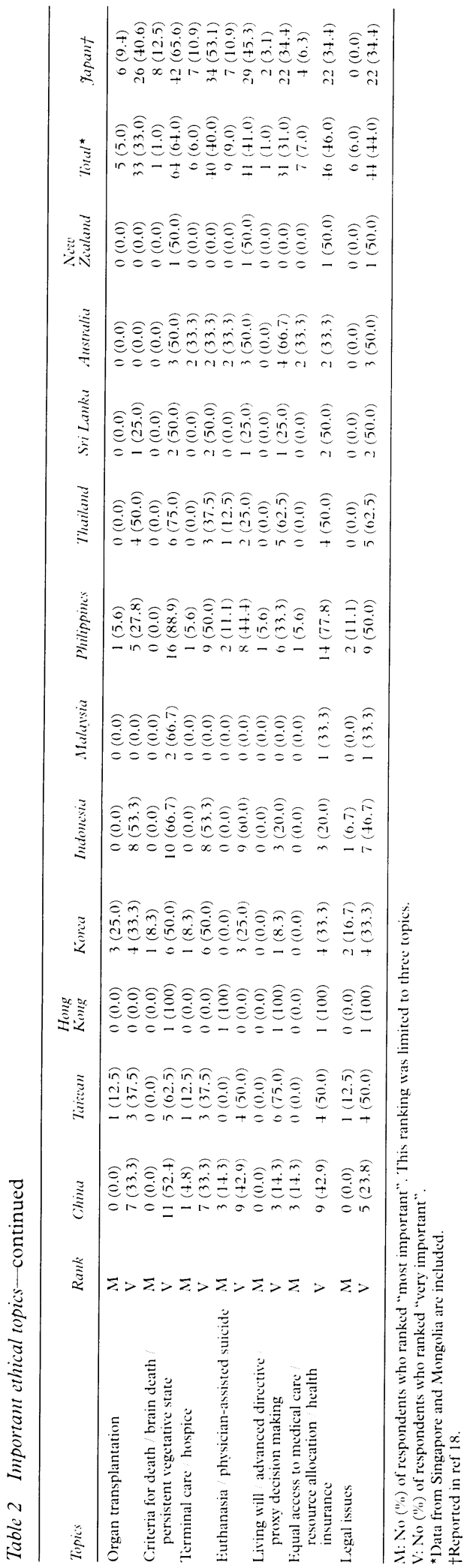

\section{Results}

MEDICAL ETHICS PROGRAMMES did not analyze countries from which few⿳亠丷厂犬 than ten per cent of questionnaires were retrieved. The response rate of the remaining 13 countris (China, Hong Kong, The Republic of Korea, Taiwan, Indonesia, Malaysia, the Philippines, Singpore, Thailand, Sri Lanka, Australia, New Z land, Mongolia), was 48.5\% (100/206), rangigg from $23 \%-100 \%$ by country.

Table 1 summarises the characteristics $\stackrel{\leftrightarrow}{0}$ courses which had lectures on ethical topics. Eighty-nine per cent (89/100) of medical schoets had some courses. Seven schools did not have $\mathscr{S}_{a}$ course, but said they would have in the noक्वे future. One Thai school answered that they djed not have a course, and did not expect to have aby course in the near future. A diversity of allocates lecture time was found in most countrifs. However, in China, Taiwan and the Philippines, $60 \%$ or more medical schools allocated more than 20 hours to ethics courses, while in Hong Kong, Korea, Indonesia, Malaysia, Thailand and $\$$ Lanka, this ratio was below $40 \%$. In every count most of the courses were compulsory. Sevent nine per cent of medical schools required studentos to take all courses, and three per cent offereol elective courses in addition to required ones. per cent of medical schools which responded \$ad they had elective courses only.

The number of medical schools offering separate medical ethics courses was $81 \%(81 / 10$ Q of all respondents. The majority of the separate courses were referred to as "medical ethics3, "bioethics", or "clinical ethics".

The longitudinal schedule, reflected in t愿 number and the schedule of the course, was diverse as any other aspect of the curriculum. 而 China, Taiwan and Malaysia, more than $60 \%$ gf medical schools reported one course, while in Hong Kong, the Philippines, Thailand, Sri Lank욜, Australia and New Zealand, two or more coursess were more common than one course. In partic $\frac{{ }^{P}}{T^{2}}$ lar, in the Philippines, Australia and Ned Zealand, $60 \%$ or more replied that they offer three or more courses. The schedule of ethic teachings was found to differ widely by country. ho China, Korea, and Indonesia, the number of medical schools offering ethics courses during BST school years was less than half. In contrast, 苑 Taiwan, Hong Kong, Malaysia, the Philippine尔, Sri Lanka, and Australia, ethics courses we scheduled during BST $^{-}$school years in $60 \%$ of schools, or more. Medical schools offering ethis both before and during BST school years we found in most countries. In the Philippines, Tha land, Sri Lanka, Australia, and New Zealand, 30 
or more of schools had this kind of multi-stepped schedule.

The analysis of diversity in teacher specialty was limited to cases in which specialties could be identified concretely enough to be categorised into four groups. Fifty-eight per cent of medical schools reported that persons with medical backgrounds were teaching ethics. The proportion of medical schools featuring philosopher/ethicist, theologian priest/monk, and lawyer/jurist/social scientist, were $27 \%, 11 \%$, and $10 \%$, respectively. Theologian/priest/monk, and/or lawyer/jurist were reported to be teaching medical ethics in a limited number of countries.

\section{ATTITUDE OF RESPONDENTS TO ETHICS EDUCATION}

We mailed the questionnaire to deans and requested them to express their personal opinions. However, it should be noted that we could not correctly identify the person(s) who directly answered the questionnaire. Therefore, we do not describe the attitude of respondents as that of "deans".

The number of respondents who were "satisfied" or "moderately satisfied" reached $80 \%$ in China, Taiwan, the Philippines, Thailand and Australia, while in Korea and Malaysia, this ratio was 50 to $60 \%$ or lower (table 1). Eighty-three per cent of all respondents considered ethics education to be "very important" compared with other subjects (not shown in the tables). However, fewer respondents thought more time should be allocated to ethics courses.

Table 2 shows which topics the respondents thought ought to be covered in lectures during medical ethics courses at their schools. "Physicians' obligations/etiquette" was evaluated as the most important topic by $64 \%$ of all respondents. "Patient's right/autonomy," "informed consent," and "patient's privacy/confidentiality", were all highly evaluated, but the ratio of respondents who chose these as "most important" decreased to $40 \%, 24 \%$, and $15 \%$ respectively. On the other hand, the evaluation was diverse and may reflect some difference between countries for specific items. "Artificial abortion" was considered as "most important" or "very important" by $78 \%$ of Filipino respondents and $73 \%$ of Indonesian respondents. However, in China, Thailand, and Australia the figure did not reach $30 \%$. "Population control" was highly evaluated in China. "The care of children, the rights of children" received high evaluation in Thailand, Malaysia, the Philippines and Sri Lanka.

\section{Discussion}

Our survey has shed some light on both similarities and differences in medical ethics education in Asian countries. It is obvious that medical ethics education has become a universal component of undergraduate formal medical training in most countries. Except for Japan, where many schools were not teaching medical ethics in separate courses, and China, where the data of nonrespondents might significantly alter the results, medical ethics was commonly taught in required separate courses. We could not obtain detailed data which would illustrate how the ethics programme had been developed in each school reported herein. Nevertheless, the development appears to have occurred in the last two decades, ${ }^{19-21}$ as in many Western medical schools. It should be noted that the spread of formal medical ethics education is not limited to industrialised countries, where high-tech medicine forces physicians to face new ethical dilemmas which are familiar in the literature of bioethics. Also, in developing countries, where physicians are required to cover a large population, with high-tech medicine usually beyond their reach, medical schools are becoming aware of ethical dilemmas unique to their own medical and sociocultural context, and that students should be prepared for these dilemmas.

On the other hand, there were many different sorts of medical ethics teaching programmes. One of the most conspicuous differences was found between Japan and other countries. In all countries except Japan, courses dealing with ethical topics were separate ones, mostly with explicit titles such as "medical ethics" or "bioethics". However, the majority of Japanese medical schools were teaching medical ethics as a unit of "introduction to medicine" or similar courses. This was not likely to be due to the matter of wording or translation. The original Japanese for "introduction to medicine," igaku gairon, has been defined and translated in various ways (ie "the philosophy of medicine"22 or "medical humanities" 23 ) since its establishment in 1942. By any definition, it aims to cover a broad spectrum of humanities and social sciences which will form a foundation for the study of medicine. Thus, the goal of "introduction to medicine" is similar to that of the medical humanities. However, quite a few Japanese medical schools seemed to allocate only a short time to ethical topics in their courses, ${ }^{24}$ and most Japanese deans did not feel their ethics teaching was well organised. ${ }^{25}$ In the Japanese survey, ${ }^{18}$ the number of Japanese medical schools offering separate medical ethics courses was 14 (22\% of 64 schools responded), but this 
figure was a leap from 7 ( $9 \%$ of 80 respondents) in $1990 .{ }^{24}$ Furthermore, Japanese respondents were the least satisfied with their ethics education. Putting all accounts together, offering medical ethics in separate courses is becoming a common feature of Asian medical schools, including Japanese ones.

From the standpoint of vertical integration, medical ethics should be taught step by step throughout preclinical and clinical education. The results suggest that the structure of vertical integration in this area was divided into four stages. Medical ethics is given as either: (1) a single course before BST school years (dominant in China and Korea; (2) a single course during BST school years (dominant in Taiwan and Malaysia); (3) multiple courses during BST school years and other years (dominant in the Philippines and Australia), or (4) a unit of courses not specified for medical ethics before BST school years (dominant in Japan). Judging from the longitudinal structure of the programme, the third pattern appears to be the most explicit mode of the vertically integrated programme, in which medical ethics literally recurs through preclinical and clinical training, as recommended by Western observers. ${ }^{23}$ Medical ethics curricula categorised in other groups seemed to be suffering from the absence of either preclinical or clinical ethics education. It can be argued that preclinical and clinical ethics education have different goals from each other, and that both are indispensable. This standpoint appears to be becoming accepted in many Asian countries, because the vertically integrated programme was found in most countries surveyed herein. At the same time, the wide range of differences in the patterns within countries suggested that the longitudinal cohesiveness of ethics education is still of less concern to medical educators in this area. The importance of longitudinal cohesiveness has only been recognised very recently, and it might be a hard task for medical schools where the curriculum is overcrowded, to introduce another set of courses throughout multiple school years.

Our results indicated that, on the one hand, interdisciplinary teaching was popular in many schools, but on the other hand, that teachers with religious backgrounds only took a modest part in the teaching of medical ethics. Modern academic medical ethics, or bioethics, has been developed as a secular discipline, dominantly influenced by the Anglo-American social context, even though there has been a significant contribution by theologians to its development. Our data suggest that medical ethics teaching at Asian medical schools has a secular character. However, the dominance of secular teachers raised questions about educatio on sensitive ethical issues such as abortion and euthanasia where there can be conflicts between medical conduct and religious beliefs. Most Asio countries maintain diverse, and sometimes co flicting, traditional religious beliefs or socigi habits. Furthermore, the conflict between modes medicine and traditional values is very often hav to mediate. The diversity observed in the respondents' evaluation of ethical topics suggess the contents of medical ethics education cán differ, perhaps reflecting the sociocultural anç historical context in which the medical schoa stands. Therefore, in the educational setting teachers need carefully to address this confliç, especially when no one from the religious camp ${ }_{9}$ participating in the programme. In this regarel interdisciplinary teaching was highly appreciate by deans; respondents expected more diversi than the current teachers had. The recruiting of more lecturers can be done without a drastic reformation of the curriculum, without needing to hire full-time teachers, and without having $\$$ establish an independent department or pre gramme. However, the successful institutionalis tion of medical ethics education would be hard te achieve without a core responsible organisation The form of the core organisation could Eary according to the availability of multidisciplicaing teachers, and the support of the dean and the lege. Therefore, the most serious weaknesses $\overline{\mathrm{gf}}$ Asian medical ethics education may be that onlyê few countries have centres for training teachers and that the standardisation or qualification $\mathrm{Qf}$ medical ethics teachers is still poorly developed

\section{Exchanging experiences}

On the basis of our survey we can say that the teaching of medical ethics is obviously widespread in the South and the East. Therefore, it may not true to describe modern medical ethics as a discopline unique to the industrialised West. Rather, medical ethics education, like other disciplines, should be taken to be an essential part of medicat education that is mandated to meet society's need for a supply of competent practitioners. On thet other hand, the diversity in vertical integration of the programmes suggested a difference of conten or goals of medical ethics teachings. The re ommendation for an integrated programme, as pषit forward by Western observers, seems grounded the practical character of medical ethics, and tige belief that it should be incorporated as a unit of clinical education. In countries like Japan, whiकृ has traditionally taken medical ethics education $\overrightarrow{\mathrm{g}}$ a unit of medical humanities, and given it character resembling liberal education, it is not yê 
certain how medical ethics will be given a practical character, and integrated into clinical education. Although setting goals, designing programmes, and recruiting appropriate teachers are left for each country and each medical school to decide, these tasks would be harder to achieve without the accumulation of empirical study in the field. Therefore, exchanging experiences may be the most feasible method for Asian medical schools to establish well-organised programmes of medical ethics education.

\section{Acknowledgements}

The authors wish to thank all participants who were involved in the studies, and Dr Darryl Macer of Tsukuba University, for his critical review of the questionnaire and this manuscript. This study was partly supported by the TOYOTA foundation, and by grant-in-aid for scientific research No 07672437 by the Ministry of Education, Science, Sport and Culture, Japan.

Michio Miyasaka, PhD, (corresponding author), is Lecturer in the School of Health Sciences, Faculty of Medicine, Niigata University, Niigata City, Fapan. Akira Akabayashi, MD, PhD, is Lecturer in The School of Health Sciences and Nursing, The University of Tokyo, Tokyo, fapan. Ichiro Kai, MD, PhD, MPH, is Professor in The School of Health Sciences and Nursing, The University of Tokyo, Tokyo. Gen Ohi, MD, PhD, MPH, is Director General of The National Institute for Environmental Studies,Tsukuba City, fapan.

\section{References and notes}

1 Veatch RM, Sollitto S. Medical ethics teaching: report of a national survey. Fournal of the American Medical Association 1976;235:72-6.

2 Institute of Medical Ethics. Report of a working party on the teaching of medical ethics (the Pond Report). London: IME Publications, 1987.

3 Miles SH, Lane LW, Bickel J, Walker RM, Cassel CK. Medica ethics education: coming of age. Academic Medicine 1989;64: 705-14.
4 Benatar SR. Teaching medical ethics. QfM 1994;87:759-67.

5 Fox E, Arnold RM, Brody B. Medical ethics education: past, present, and future. Academic Medicine 1995;70:761-79.

6 Baylis F, Downie J. Undergraduate medical ethics education: a survey of Canadian medical schools. London: Westminster Institute, 1990.

7 Forrow L, Arnold R. Bioethics education, II. Medicine. In: Reich WT, ed. Encyclopedia of bioethics [rev ed]. New York: Simon \& Schuster Macmillan, 1995:259-64.

8 Teachers of medical ethics and law in UK medical schools Teaching medical ethics and law within medical education: a model for the UK core curriculum. Fournal of Medical Ethics 1998;24:188-92.

9 Hope T. Ethics and law for medical students: the core curriculum. Fournal of Medical Ethics 1998;24:147-8.

10 Callahan D. Bioethics. See reference 7:247-56.

11 Annas GJ. Origin and nature of patients' rights. See reference 7:1925-7.

12 Veatch R. Death, dying and the biological revolution: our last quest for responsibility. New Haven: Yale University Press, 1976.

13 Walter JJ. Quality of life in clinical decisions. See reference 7:1352-58

14 Fox RC. The evolution of American bioethics. In Weisz G, ed. Social science perspectives on medical ethics. Dordrecht, the Netherlands: Kluwer, 1990:201-17.

15 Sakamoto $\mathrm{H}$. The foundation of east asian bioethics. Beijing, China. East Asian Conference on Bioethics, 1995 Nov 3-5.

16 Ohi G, Takei H. An anthropological view regarding bioethics. Tsukuba, Japan. Ninth Japanese Bioethics Conference 1997.

17 World Health Organisation. World directory of medical schools [6th ed]. Geneva: World Health Organisation, 1988.

18 Akabayashi A, Miyasaka M, Kai I, Ohi G. Survey of medical ethics education in Japanese medical schools. Medical Education (Fapan) 1999;30:47-53 (in Japanese).

19 Babapulle CJ. Teaching of medical ethics in Sri Lanka. Medical Education 1992;26:185-9.

20 Shirahama M. The clinical ethics education in Saga Medical School. Fournal of Japan Association for Bioethics 1996;6:57-61.

21 Alora A. Bioethics in the Philippines. Beijing, China. East Asian Conference on Bioethics, 1995 Nov 3-5.

22 Omodaka H. Igaku gairon towa. Tokyo: Seishin-Shobo, 1987 (in Japanese).

23 Igaku gairon joron. In: "igaku gairon" henshu iinkai, ed. Akita daigaku igakubu igaku gairon 1994. Akita, Japan: Hondo Igaku Shinkokai, 1995.

24 Mori C, Nishio T. Survey of curriculum in the medical humanities at japanese medical schools - a comparative study between an initial survey in 1988 and a second survey in 1994 Medical Education (fapan). 1996;27:155-9 (in Japanese).

25 Hoshino K. Report of a basic study on bioethics education in fapan. (Wagakuni ni okeru seimeirinri kyoiku ni kansuru kisoteki kenkyu) 1987. This report was written, edited and published by the study group itself. Kazumasa Hoshino, who was then a professor in Kyoto University, Kyoto, Japan, was the chief researcher of the group.

26 Nolen AL, Coutts MC, eds. International directory of bioethics organizations. Bioethics resource series, vol. 1. Washington, DC: Kennedy Institute of Ethics, Georgetown University, 1993. 